\title{
Snapshot: Logo Vignettes: Early Teachable Moments
}

\author{
Uri Wilensky
}

Published online: 13 October 2013

(C) Springer Science+Business Media Dordrecht 2013

In this snapshot, Wally Feurzeig, one of the originators of Logo, and an innovative designer of mathematics education learning environments, recalls some compelling vignettes from the early history of Logo (including activities with the first Logo-controlled wireless turtle), with children ranging in age from pre-schoolers to fifth-graders. Wally passed away this past year. Wally was a long-time member of the IJCML/TKL board and a highly valued contributor to the field. We at TKL as well as the wider field miss him.

This column will publish short (from just a few paragraphs to ten or so pages), lively and intriguing computer-related mathematics vignettes. These vignettes or snapshots should illustrate ways in which computer environments have transformed the practice of mathematics or mathematics pedagogy. They could also include puzzles or brain-teasers involving the use of computers or computational theory. Snapshots are subject to peer review. From the Column Editor Uri Wilensky, Northwestern University, e-mail: uri@northwestern.edu.

U. Wilensky $(\bowtie)$

Northwestern University, Evanston, IL, USA

e-mail: uri@northwestern.edu 